\title{
Evaluation of resequencing on number of tag SNPs of 13 atherosclerosis-related genes in Thai population
}

\author{
Chintana Tocharoentanaphol $\cdot$ Somying Promso $\cdot$ Dianna Zelenika $\cdot$ \\ Tassanee Lowhnoo $\cdot$ Sissades Tongsima $\cdot$ Thanyachai Sura $\cdot$ Wasun Chantratita \\ Fumihiko Matsuda $\cdot$ Sean Mooney $\cdot$ Anavaj Sakuntabhai
}

Received: 24 August 2007/Accepted: 29 October 2007/Published online: 28 November 2007

(C) The Japan Society of Human Genetics and Springer 2007

\begin{abstract}
In the candidate gene approach, information about the distribution of single nucleotide polymorphisms (SNPs) is a crucial requirement for choosing efficient markers necessary for a case-control association study. To obtain such information, we discovered SNPs in 13 genes related to atherosclerosis by resequencing exon-flanking regions of 32 healthy Thai individuals. In total, 194 polymorphisms were identified, 184 of them SNPs, four insertions, and the rest deletions. Fifty-nine of the SNPs were characterized as novel polymorphisms, and these accounted for $30 \%$ of the identified SNPs. Comparing allele frequency distributions of the Thai population with other Asian populations shows similar patterns. In contrast, a low correlation pattern $(r=0.521)$ was found when comparing with either Caucasian or African populations. However, some rare alleles (rs11574541 and rs10874913) are found in the Thai population but not in other Asian populations. Most of the novel SNPs found were located outside the haplotype blocks generated by known SNPs in the
\end{abstract}

Chintana Tocharoentanaphol and Somying Promso contributed equally to this work.

C. Tocharoentanaphol - D. Zelenika - T. Lowhnoo · F. Matsuda Centre National de Génotypage, 2 rue Gaston Crémieux, CP 5721, 91057 Evry Cedex, France

C. Tocharoentanaphol $(\bowtie)$

Chulabhorn Cancer Centre, Viphavadee-Rangsit road, Laksi, Bangkok 10120, Thailand

e-mail: chintaphol@hotmail.com

S. Promso · W. Chantratita

Department of Pathology, Faculty of Medicine Ramathibodi

Hospital, Mahidol University, Bangkok 10400, Thailand

T. Lowhnoo

Research center, Faculty of Medicine Ramathibodi Hospital,

Mahidol University, Bangkok 10400, Thailand
Thai population. Only 5.77\% of the novel SNPs lies in these defined haplotype blocks. The selection of haplotype-tagging SNPs shows that 8 of 13 genes benefited from the ethnicspecific genotype information. That is, when at least one novel SNP was present, the tagging SNPs chosen were altered. Functional prediction of 16 nonsynonymous SNPs (nsSNPs) by three different algorithm tools demonstrated that five nsSNPs possibly alter their corresponding protein functions. These results provide necessary information for conducting further genetic association studies involving the Thai population and demonstrate that resequencing of candidate genes provides more complete information for full genetic studies.

Keywords Thai - Atherosclerosis - SNP · Tag SNP · Resequencing · Novel SNP

\section{Introduction}

Cardiovascular disease (CVD) has been one of the leading causes of death in the Thai population over the last decade

\section{S. Tongsima}

National Center for Genetic Engineering and Biotechnology, Pathumthani, Thailand

T. Sura $\cdot$ A. Sakuntabhai

Department of Medicine, Faculty of Medicine Ramathibodi

Hospital, Mahidol University, Bangkok 10400, Thailand

A. Sakuntabhai

Laboratoire de Génétique de la réponse aux infections chez

l'homme, Institut Pasteur, 75724 Paris Cedex 15, France

S. Promso $\cdot$ S. Mooney

Center for Computational Biology and Bioinformatics, Department of Medical and Molecular Genetics, Indiana University School of Medicine, Indianapolis, IN 46202, USA 
(Department of Medical Service Thailand 2006a). Atherosclerosis is one of the major factors among cardiovascular disease (Department of Medical Service Thailand 2006b). It is characterized by abnormal fatty deposits and fibrosis of the inner layer of arteries. This progressive disease normally takes years to manifest itself as a partial or complete interruption of blood flow. Depending on the artery affected, atherosclerosis can lead to a life-threatening condition. However, the risk of atherosclerosis is influenced by many factors, such as body mass index (BMI), blood pressure, plasma lipid levels, genetics, and environment. A number of genetic factors have shown significant correlation to processes related to atherosclerosis (Laukkanen and YlaHerttuala 2002). Currently, candidate-gene-based association studies are the most common approach used in diseasecausing gene identification research. Resequencing is a technique for SNP typing and discovery and is useful for fine mapping as well as discovery of unique single nucleotide polymorphisms (SNPs) for ethnic groups in a specific gene. SNP discovery is then an alternative choice for SNP typing prior to starting a case-control association study using a candidate gene approach (Do et al. 2006).

Inflammation plays an essential role in the etiology and progression of atherosclerosis. Simon et al. (2000) presented evidence that inflammation also has a role in vascular repair after mechanical arterial injury. Several genes involved in inflammation processes have been reported, namely, ITGAM, ITGAX, ITGB7, and SELPLG. The cell adhesion molecules, such as ITGAM (Integrin, alpha $\mathrm{M}$ ) and ITGAX (Integrin, alpha $\mathrm{X}$ ), are important in the adherence of monocytes to stimulate endothelium as well as in the phagocytosis of complement-coated particles. ITGB7 (Integrin, beta 7) is also expected to play a role in adhesive interactions of leukocytes by being a receptor for fibronectin, whereas SELPLG (Selectin P lingand) is the high-affinity counter-receptor for $\mathrm{P}$-selectin on myeloid cells and stimulates $\mathrm{T}$ lymphocytes, where it plays a critical role in the tethering and rolling of these cells to activate platelets or endothelia expressing P-selectin (Schneider et al. 2004).

The CCL1-chemokine (C-C motif) ligand 1 and CCL2chemokine ( $\mathrm{C}-\mathrm{C}$ motif) ligand 2 belong to the $\mathrm{CXC}$ subfamily of the cytokine group, which is involved in immunoregulatory and inflammatory processes. This cytokine displays chemotactic activity for monocytes and basophils but not for neutrophils or eosinophils (Maglott et al. 2005). Recent studies reported that CCL2 or MCP-1 is involved in the pathogenesis of human atherosclerosis and myocardial infarction. This evidence also agrees with the hypothesis that this group is involved in inflammation (McDermott et al. 2005; Tabara et al. 2003).

In addition to the role of an anti-inflammatory cytokine, the role of transforming growth factor $\beta$ (TGF- $\beta$ ) in atherosclerosis has been the subject of considerable debate for a decade (Singh and Ramji 2006). TGFB2 (TGF- $\beta$ 2) and TGFB3 (TGF- $\beta$ 3) show significant mRNA expression differences in atherogenic animal models (Tabibiazar et al. 2005; Wang et al. 2003). TGFBR2 (TGF- $\beta$ type II receptor) defects have been recently associated with Marfan syndrome (MFS) with a prominent cardioskeletal phenotype (Disabella et al. 2006; Matyas et al. 2006; Mizuguchi et al. 2004).

Many studies support that lipid plays a major role in the formation of atheromatous plaque. High density lipoprotein (HDL) is negatively correlated with risk of CVD (Asztalos 2004). Genes involved in lipid transport, such as APOAI (apolipoprotein A-I), SCARB1 (scavenger receptor class B, member1), and LIPG (lipase, endothelial) may also be predisposed to the disease. APOAl is the major protein component of HDL in plasma. Previous studies have reported that SNPs, including $-75[\mathrm{G} / \mathrm{A}]$ in the APOA1 promoter, are significantly associated with HDL cholesterol (HDL-C) variability (Brown et al. 2006; Ruano et al. 2006). SCARBI is an HDL receptor that mediates selective cholesterol uptake from HDL to cells. McCarthy et al. (2003) examined polymorphisms in the HDL receptor gene SCARB1 in 371 Caucasian patients suffering from coronary artery disease to determine their association with plasma lipids. They found an association between a combination of genotypes to the disease; however, this association was found only in women. One of their findings was that the genetic variants in SCARBI may be an important determinant of abnormal lipoproteins in women, which confers particular susceptibility on coronary artery disease (McCarthy et al. 2003). LIPG, a new member of the triglyceride lipase family, is expressed in endothelial cells (Jaye et al. 1999) and may have indirect atherogenic actions in vivo through its effect on circulating HDL-C and directly mediates cellular lipoprotein uptake (Fuki et al. 2003; Ishida et al. 2004).

Nowadays, many studies testing common SNPs associated with higher risk of developing common disease was done by using available SNP databases. When commercial microarray genotyping chips are applied to genetic studies, most SNPs in the databases come from the common SNPs in the Caucasian population exclusively. It is not yet clear whether public SNP databases are adequate for studies on other ethnic groups, such as the Thai population.

In this study, these 13 atherosclerosis-candidate genes were resequenced focusing on exons flanking regions in the Thai population. Using 32 unrelated healthy Thai DNA samples, this study established common genetic variation in these regions. We compared many parameters [allele frequency, ethnic differences, linkage disequilibrium (LD) block, and tags SNPs] needed for association study by using two data sets: (1) our resequencing data, which include all novel SNPs found in our study, and (2) only SNPs available in the public SNP databases and excluding novel SNPs. 


\section{Materials and methods}

DNA sample

The 32 healthy Thais were recruited in this study and were blindly picked from the 64 healthy individuals conducted under the Thailand SNP Discovery Project. To capture the genetic makeup of Thais, all recruited individuals' families must have resided in Thailand for more than two generations. To avoid late-onset unhealthy samples, the individuals must be at least 50 years of age with no medical history of chronic diseases such as hypertension, diabetes mellitus, and cancer. Informed consent was obtained from each participant.

Resequencing analysis for polymorphism identification

Total genomic DNA from these 32 unrelated Thai individuals was isolated from peripheral leukocytes or Epstein-Barr virus (EBV)-transformed B lymphocytes by using the standard phenol-chloroform extraction method. The same amount of the two DNA samples was pooled together. SNPs were analyzed by direct sequencing of the pooled DNA samples. Before using, the pooled DNA was tested with a known SNP assay to test feasibility of using pooled DNA. For all genes analyzed, polymerase chain reaction (PCR) primers were newly designed by using Primers3 software (Rozen and Skaletsky 2000). The PCR targets included all exons based on GenBank; NT_033899 (APOA1), NT_010799 (CCL1), (CCL2), NT_010393 (ITGAM and ITGAX), NT_029419 (ITGB7), NT_010966 (LIPG), NT_009755 (SCARB1), NT_019546 (SELPLG), NT_021877 (TGFB2), NT_026437 (TGFB3), NT_032977 (TGFBR2), and NT_022517 (TGFBR3). Each exon was amplified separately and sequenced in both directions. PCR conditions and primer oligo sequences are available on the ThaiSNP database Web site (http://thaisnp2.biotec.or.th). Sequencing was performed using BigDye (Applied Biosystems) on an ABI 3730 DNA sequencer, according to the manufacturer's instruction. Sequence comparison, SNP discovery, and allele frequency were determined using Genalys program version 3.326a (Takahashi et al. 2002) and verified with visual inspection by two independent individuals. Before analysis, each chromatogram was trimmed to remove low-quality sequence.

Data and statistical analysis

Analysis of the resequencing of 16 pooled DNAs for each gene was performed using the Pool2 Package (Hoh et al. 2003). Based on the estimated frequencies, the Pool2 statistically calculates individual genotypes. The haplotypes were then estimated by using pairwise LD, statistics and the haplotype blocks were defined using confidence intervals (Gabriel et al. 2002) through the Haploview software package (Barrett et al. 2005). The ethnic group correlation was determined by comparing minor allele frequency (MAF) to dbSNP and HapMap data;-Caucasian, African, Japanese, and Chinese-using Pearson's moment correlation and Fisher's exact test function of the R-package software (R Development Core Team 2006). Statistical significance was determined at a two-sided value of $P<0.001$ with 500,000 replications using the Monte Carlo test.

Tag SNPs of each gene were selected by using the aggressive tagging algorithm (de Bakker et al. 2005) within the Haploview software package. The calculation was applied to each gene in two categories: ThaiSNP data excluding novel SNPs, and ThaiSNP data including novel SNPs. All parameters were used according to the program's default, for which log of odds (LOD) threshold for multimarker tests was set as 3.0 and the default $r^{2}$ threshold was used (0.8). Differences in the number of tag SNPs in both conditions were compared using the tagging efficiency parameter. This parameter was calculated from the percentage of the ratio between the differences of the number of tagging SNPs found in the same gene with novel SNPs and without novel SNPS. Tag SNP efficiency $=\left(N_{\mathrm{RT}}-N_{\mathrm{DT}}\right) /$ $\left(N_{\mathrm{R}}-N_{\mathrm{D}}\right) 100$, where $N_{\mathrm{RT}}$ is the total number of tag SNPs selected from resequencing data, $N_{\mathrm{DT}}$ is the total number of tag SNPs selected from the SNP data verified by the National Center for Biotechnology Information (NCBI), $N_{\mathrm{R}}$ is the total number of SNPs from the resequencing process, and $N_{\mathrm{D}}$ is the total number of SNPs validated by the NCBI. $N_{\mathrm{RT}}-N_{\mathrm{DT}}$ is the total number of tag SNPs additionally discovered after resequencing, whereas $N_{\mathrm{R}}-N_{\mathrm{D}}$ is the total number of new SNPs additionally discovered after resequencing. When there is no new SNPs, $N_{\mathrm{R}}-N_{\mathrm{D}}=0$, which means that no additional SNPs were found from resequencing and there is no additional tag SNPs. The higher percentage will represent the impact of novel SNPs to effect tag SNP selection, whereas zero means those novel SNPs were not found and were not gaining information.

Assessment of nonsynonymous SNPs

All SNPs identified in this study were mapped onto the human genome using NCBI Refseq (genome_build 36.1) and dbSNP (build126). The nonsynonymous SNPs (nsSNPs) were analyzed using SIFT (Ng and Henikoff 2002), PolyPhen (Ramensky et al. 2002), and SNPs3D (Yue et al. 2006) for assessing the potential impact of amino acid substitution on protein function. Those three 
tools were performed using their respective Web sites. SIFT (http://blocks.fhcrc.org/sift/SIFT.html) and PolyPhen (http://genetics.bwh.harvard.edu/pph/index.html) were run using the services on their Web sites with the default parameters. SNPs3D (http://www.snps3d.org/) scores were determined by the sequence-based NCBI scores provided on the Web site.

\section{Results}

In the identification of novel polymorphisms in the Thai population, the resequenced regions spanned a total of $453,533 \mathrm{bp}$ and covered around $1 \mathrm{~kb} 5^{\prime}$ upstream from the starting codon and around $1 \mathrm{~kb}$ after the $3^{\prime}$ stop codon. We identified 194 polymorphisms from 16 pooled DNA samples located on the 13 atherosclerosis candidate genes, which comprised 184 SNPs, four insertions, and six deletions (Table 1). One hundred and thirty (67\%) SNPs had common allele frequencies (MAF greater than 0.05), and the rest (64; $33 \%$ ) were characterized as rare alleles (MAF less than 0.05). Figure 1 illustrates all genetic variations found in this study, separated by gene. The novel polymorphisms are indicated by an asterisk. Fifty-nine polymorphisms (30\%) were discovered by mapping their positions to the RefSeq (http://www. ncbi.nlm.nih.gov/RefSeq/) sequences mapped to the human genome in RefSeq database build 36.1 and comparing with the location of SNPs reported in dbSNP database build 126 (Table 2). Of those, 16 SNPs (27\%) were located in coding regions, whereas 43 SNPs (73\%) mapped to intronic regions. Among the novel SNPs, 11 had MAF greater than 0.05 and were located in intronic regions, whereas 15 coding SNPs had allele frequencies less than 0.05 .

Ethnic differences in genetic-variation allele frequency

To determine ethnic differences in SNP allele frequencies, we searched reported SNPs from the HapMap database (http://www.hapmap.org) and dbSNP database (http://www. ncbi.nlm.nih.gov/SNP/) and compared our data with those from other ethnic groups. Differences in allele frequency distribution could be observed among various ethnic groups (Fig. 2). The allele frequencies found in Thai populations were similar to other Asian populations, particularly the combined Japanese and Chinese (JPT.CHB) data (correlation coefficient $r=0.765$ ), but appeared as a low correlation to Caucasian (correlation coefficient $r=0.521$ ) and African (correlation coefficient $r=0.206$ ) populations. The significantly different markers among these ethnic groups are presented in Table 3. Two SNPs, rs4264407, and rs11165378, appeared monomorphic in the Thai population, whereas they were polymorphic in Caucasian and African populations. Also, rs7188189 appeared monomorphic in the Thai (data not shown) and African American populations, but it was polymorphic in European American populations (The Innate Immunity PGA 2000). In contrast, rs 11574541 located on exon \#13 of ITGB7 and rs10874913 located on intron of $T G F B R 3$ were only found in the Thai population with an MAF of 0.03 . There were some polymorphisms unique to only the Asian population, i.e., rs11057824, rs11057825, rs10482823, and rs2306888, whereas rs9936831 and rs11574635 were
Table 1 Summary of genetic variation in the 13 cardiovascular related genes

Ins/del Insertion/deletion variation, UTR untranslated region, synSNP synonymous single nucleotide polymorphism, $n s S N P$ nonsynonymous single nucleotide polymorphism

\begin{tabular}{lcrrrrrrrr}
\hline Gene & $\begin{array}{l}\text { All } \\
\text { genetic } \\
\text { variations }\end{array}$ & SNPs & $\begin{array}{l}\text { Ins/ } \\
\text { del }\end{array}$ & $\begin{array}{l}\text { Novel } \\
\text { genetic } \\
\text { variation }\end{array}$ & SynSNPs & nsSNPs & UTR & $\begin{array}{l}\text { Total base } \\
\text { pairs } \\
\text { sequenced } \\
\text { (kb) }\end{array}$ & $\begin{array}{l}\text { Frequency } \\
\text { (bp/1SNP) }\end{array}$ \\
\hline APOA1 & 10 & 9 & 1 & 2 & 0 & 1 & 2 & 2.2 & 215 \\
CCL1 & 4 & 4 & 0 & 1 & 0 & 1 & 0 & 2.7 & 678 \\
CCL2 & 4 & 4 & 0 & 0 & 1 & 0 & 1 & 1.9 & 476 \\
ITGAM & 35 & 34 & 1 & 13 & 1 & 4 & 5 & 13.0 & 371 \\
ITGAX & 25 & 25 & 0 & 14 & 4 & 3 & 5 & 11.8 & 473 \\
ITGB7 & 15 & 14 & 1 & 3 & 2 & 0 & 3 & 6.3 & 417 \\
LIPG & 25 & 24 & 1 & 7 & 1 & 2 & 13 & 7.0 & 280 \\
SCARB1 & 19 & 18 & 1 & 6 & 3 & 0 & 1 & 7.0 & 370 \\
SELPLG & 4 & 3 & 1 & 3 & 1 & 2 & 0 & 2.5 & 634 \\
TGFB2 & 7 & 5 & 2 & 2 & 0 & 0 & 3 & 4.0 & 569 \\
TGFB3 & 9 & 7 & 2 & 3 & 0 & 0 & 1 & 5.2 & 580 \\
TGFBR2 & 10 & 10 & 0 & 1 & 1 & 1 & 0 & 3.9 & 391 \\
TGFBR3 & 27 & 27 & 0 & 4 & 4 & 2 & 2 & 6.8 & 251 \\
TOTAL & 194 & 184 & 10 & 59 & 18 & 16 & 36 & 74.4 & 439 \\
\hline
\end{tabular}


a) $A P O A 1$

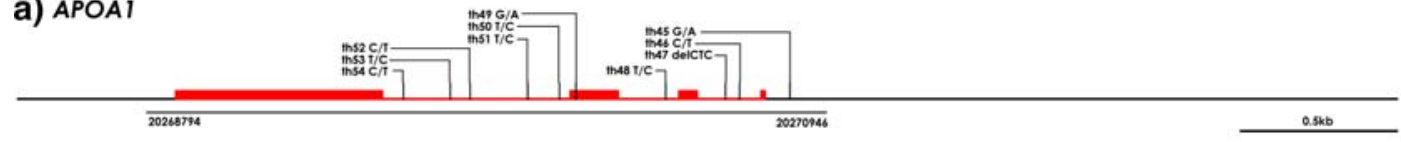

b) $\mathrm{CCLI}$

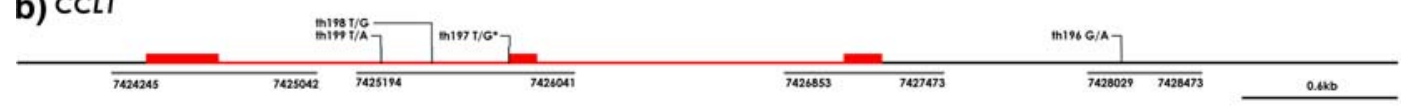

c) $\mathrm{CCL} 2$

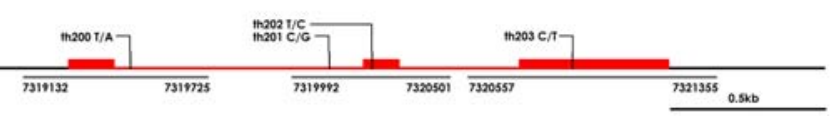

d) ITGAM

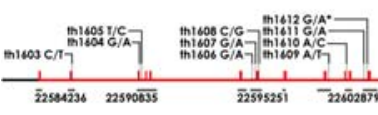

$22621753^{-22622431}$

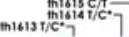

${ }^{7} 7$

22645e00

\section{e) ITGAX}

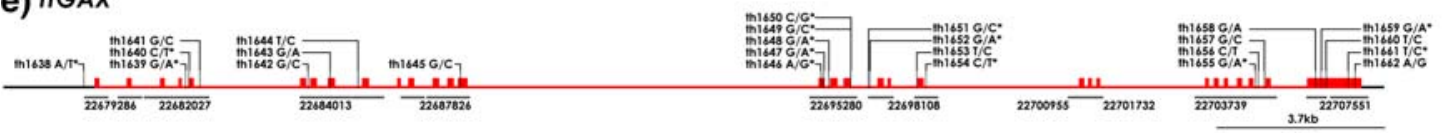

f) $1 T G B 7$

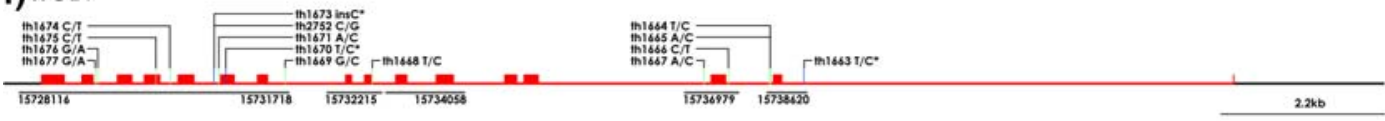

g) LIPG

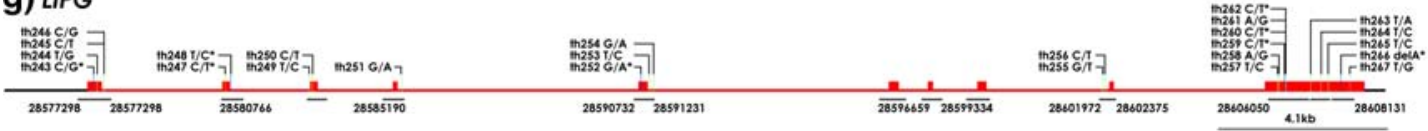

\section{h) SCARBI}

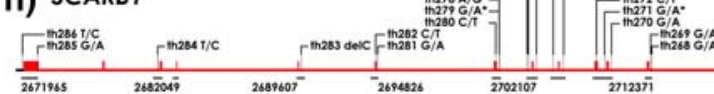

i) SELPLG

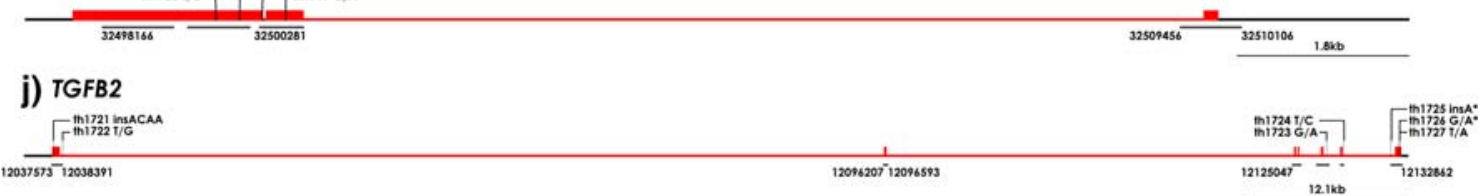

\section{k) TGFB3}

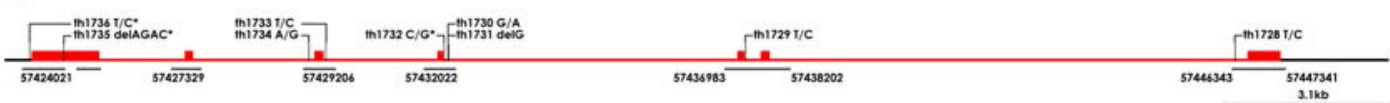

\section{I) TGFBR2}

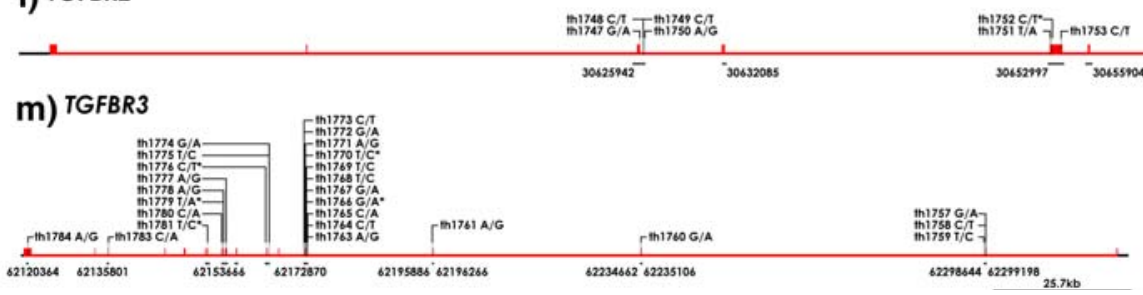


4 Fig. 1 Location of single nucleotide polymorphisms (SNPs) in the APOA1 (a), CCL1 (b), CCL2 (c), ITGAM (d), ITGAX (e), ITGB7 (f), $L I P G(\mathbf{g}), S C A R B 1$ (h), SELPLG (i), TGFB2 (j), TGFB3 (k), TGFBR2 (l), and TGFBR3 (m) genes, indicated by vertical lines. Exons are indicated by a solid rectangle. The regions that have been sequenced are indicated by a horizontal line. The polymorphism numbers are accession numbers from the ThaiSNP database (correspondence to dbSNP rsIDs is given in Tables 2 and 3). The novel polymorphisms are indicated by an asterisk. The genomic sequences used for alignment are NT_033899 (APOA1), NT_010799 (CCL1), (CCL2), NT_010393 (ITGAM and ITGAX), NT_029419 (ITGB7), NT_010966 $(L I P G)$, NT_009755 (SCARB1), NT_019546 (SELPLG), NT_021877 (TGFB2), NT_026437 (TGFB3), NT_032977 (TGFBR2), and NT_022517(TGFBR3)

polymorphic in Thai, Caucasian, and African but not in Chinese and Japanese.

Linkage disequilibrium (LD) analysis and haplotype-block definition

LD statistics $\left(D^{\prime}\right.$ or $\left.r^{2}\right)$ for the individual genotypes were calculated using the confidence intervals algorithm (Gabriel et al. 2002) implemented in the Haploview program for defining a haplotype block. To evaluate the effect the novel SNPs found in this study on the definition of haplotype blocks, we redefined the LD block in the Thai population using Thai SNPs excluding the novel SNPs (defined as known ThaiSNPs) and compared them with those from the combined Chinese-Japanese population. The populations were combined because the Japanese and Chinese populations were recently shown to be insignificantly different (The International HapMap 2005). Figure 3 shows haplotype-block definitions for the ITGB7 gene using HapMap data, Thai population data with known SNPs, and Thai population data with novel SNPs. Both combined Chinese-Japanese and Thai population data had been defined with one block, with small differences in SNP members in the block. By introducing two novel SNPs from the Thai population to the SNP set and recalculation of the haplotype blocks, both novel SNPs appeared outside the original haplotype blocks. The haplotype block was then calculated for the rest of the 13 genes (data not shown); from this, $5.77 \%$ of novel SNPs were located within the LD block defined by the known Thai SNPs reported in dbSNP.

\section{Tag SNP efficiency}

Tag SNP efficiency was calculated by the number of tag SNPs from resequencing data and the number of tag SNPs from data verified by the NCBI. We identified that eight of 13 genes achieved $100 \%$ tag SNPs among discovered novel SNPs from the resequencing process, which means all
SNPs newly discovered from the resequencing process were tagging SNPs (Table 4). In contrast, only one gene, $C C L 2$, did not benefit from resequencing, because no novel SNPs were found. ITGAM, TGFBR3, ITGAX, and $L I P G$ each had novel tag SNPs identified when the newly discovered SNPs were included. Our defined parameter, tag SNP efficiency (see "Materials and methods") of ITGAM, TGFBR3, ITGAX, and LIPG were $75.00 \%$, $66.76 \%$, $64.29 \%$, and $50.00 \%$, respectively. This suggested that a high percentage of novel SNPs define new tags. However, the overall tag SNP efficiency for all genes was $81.23 \%$.

Functional polymorphism assessment

To assess the impact of amino acid substitutions on protein activity, we analyzed 16 nsSNPs, including eight novel nsSNPs, using three nsSNP functional prediction tools that utilize different algorithms: SIFT, PolyPhen, and SNPs3D (Table 5). Eleven nsSNPs were concordantly predicted to be intolerant and seven predicted to be neutral with these three functional prediction tools, whereas the remaining five were predicted to have a mixture of neutral and damaging activity. Allele frequencies were also used to classify the potential effects of nsSNPs. Interestingly, eight out of 16 nsSNPs were common SNPs (MAF > 5\%). SNP rs2230429 located on ITGAX had the highest MAF observed (0.5) and was predicted to be damaging by all these tools.

\section{Discussion}

Cardiovascular disease is a complex disease that is influenced by many factors, including genetics. Candidategene-based association studies are the most common approach used in disease-causing gene identification research. Choosing markers for association approaches is based on extensive information on the distribution of SNPs across the genome. To obtain such information, 13 candidate genes, which had been associated to atherosclerosis, were resequenced in exon-flanking regions in the Thai population. We decreased all the possible known errors by using only high-quality chromatograms for the analysis. The sequencing data was obtained from both strands with difference primers. More than $80 \%$ of SNPs found were associated with both strands. We identified 59 novel polymorphisms $(30 \%)$ by comparing them with dbSNP build 126. The percentage of novel polymorphisms found in this study was quite similar to the other SNP discovery studies (Michiels et al. 2007), but the allele frequencies were observed to have a high number of rare alleles; as many as $45(76 \%)$ of those novel SNPs were rare alleles. 


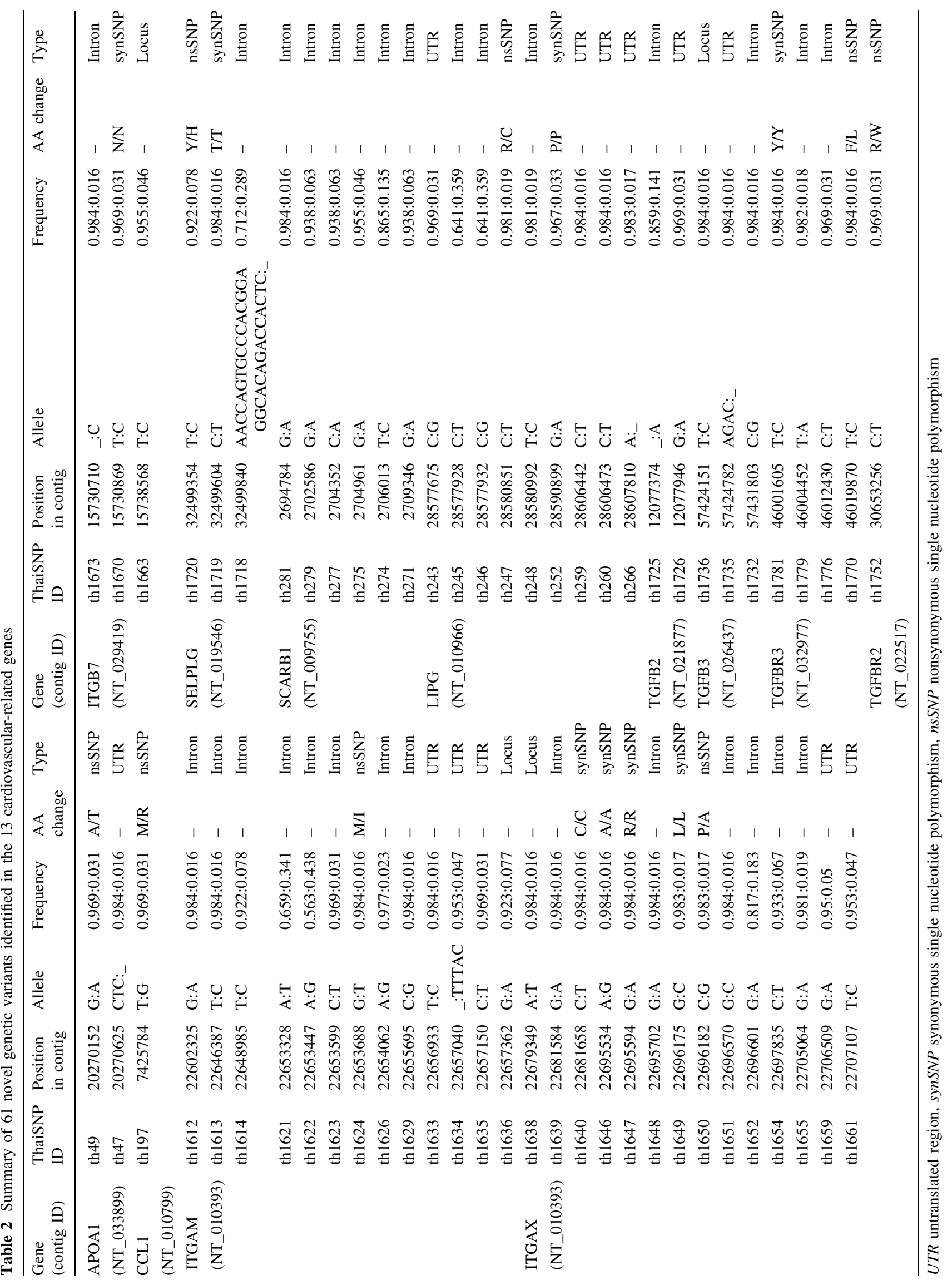


Fig. 2 Scatter plots of pairwise comparison of allele frequency distribution between Thai,

Caucasian, Chinese, Japanese, Chinese + Japanese, African, and Single Nucleotide Polymorphism Database (dbSNP). Pearson's product moment correlation of allele frequency between the two populations is presented in the lower diagonal matrix

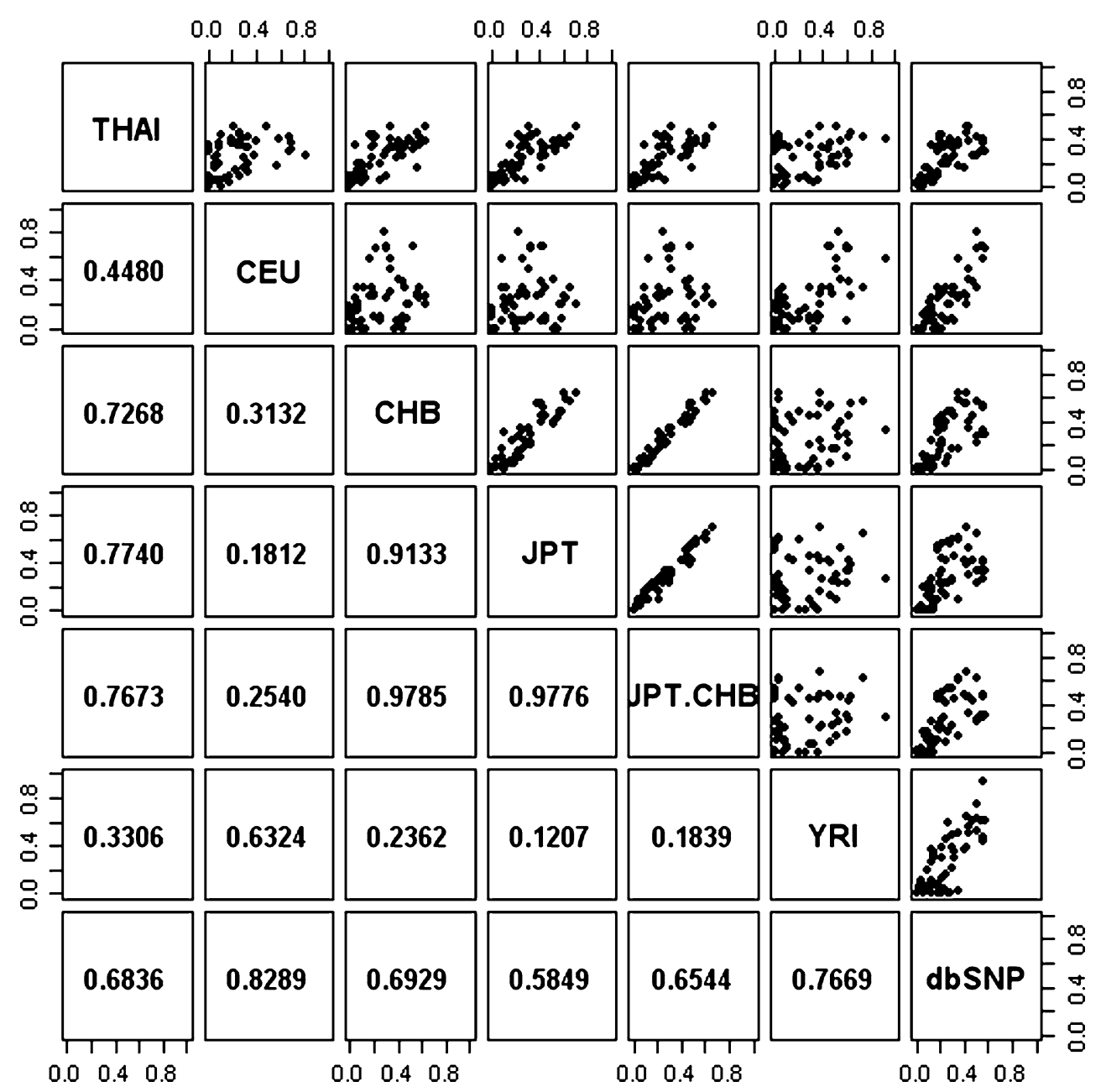

Table 3 Ethnic comparison of single nucleotide polymorphism (SNP) allele frequencies in the 13 cardiovascular-related genes

\begin{tabular}{|c|c|c|c|c|c|c|c|c|c|}
\hline \multirow[t]{2}{*}{ Gene } & \multirow[t]{2}{*}{ SNP(rs no.) } & \multirow[t]{2}{*}{ Type } & \multirow[t]{2}{*}{ Allele } & \multirow[t]{2}{*}{ Thai $^{\mathrm{a}}$} & \multicolumn{4}{|l|}{ Hapmap $^{\text {b }}$} & \multirow{2}{*}{$\begin{array}{l}\text { Ethnic } \\
\text { difference }\end{array}$} \\
\hline & & & & & Caucasian & Han Chinese & Japanese & African & \\
\hline CCL1 & rs2282691 & Intron & $\mathrm{A}: \mathrm{T}$ & $0.375: 0.625$ & $0.404: 0.596$ & $0.405: 0.595$ & $0.523: 0.477$ & $0.551: 0.449$ & 0.176 \\
\hline CCL2 & rs 4586 & synSNP & $\mathrm{T}: \mathrm{C}$ & 0.583:0.417 & $0.667: 0.333$ & $0.422: 0.578$ & 0.352:0.648 & $0.258: 0.742$ & 0.409 \\
\hline \multirow[t]{7}{*}{ ITGAM } & rs1143678 & nsSNP & $\mathrm{C}: \mathrm{T}$ & 0.933:0.067 & $0.867: 0.133$ & 0.989:0.011 & $1.000: 0.000$ & $0.8: 0.2$ & 0.2 \\
\hline & rs3815801 & Intron & A:G & 0.672:0.328 & $0.667: 0.333$ & $0.822: 0.178$ & 0.739:0.261 & 0.608:0.392 & 0.214 \\
\hline & rs4077810 & Intron & $\mathrm{C}: \mathrm{T}$ & 0.568:0.432 & $0.737: 0.263$ & 0.841:0.159 & $0.775: 0.225$ & 0.966:0.034 & 0.398 \\
\hline & rs4597342 & UTR & $\mathrm{C}: \mathrm{T}$ & 0.607:0.393 & $0.724: 0.276$ & $0.8: 0.2$ & 0.705:0.295 & 0.967:0.033 & 0.36 \\
\hline & rs7184677 & Intron & G:A & 0.938:0.062 & 0.892:0.108 & 0.989:0.011 & $1.000: 0.000$ & $0.642: 0.358$ & 0.358 \\
\hline & rs7206295 & Intron & $\mathrm{C}: \mathrm{T}$ & $0.65: 0.35$ & $0.717: 0.283$ & $0.8: 0.2$ & $0.705: 0.295$ & 0.967:0.033 & 0.317 \\
\hline & rs9936831 & Intron & $\mathrm{A}: \mathrm{T}$ & 0.95:0.05 & 0.9:0.1 & $1.000: 0.000$ & $1.000: 0.000$ & $0.636: 0.364$ & 0.364 \\
\hline \multirow[t]{5}{*}{ ITGAX } & rs11150620 & Intron & $\mathrm{G}: \mathrm{C}$ & 0.654:0.346 & $0.75: 0.25$ & $0.42: 0.58$ & $0.386: 0.614$ & 0.975:0.025 & 0.589 \\
\hline & rs1140195 & UTR & A:G & 0.609:0.391 & $0.737: 0.263$ & $0.367: 0.633$ & 0.398:0.602 & 0.975:0.025 & 0.608 \\
\hline & rs11574635 & Intron & G:C & 0.917:0.083 & $0.828: 0.172$ & $1.000: 0.000$ & $1.000: 0.000$ & $0.737: 0.263$ & 0.263 \\
\hline & rs2929 & UTR & $\mathrm{G}: \mathrm{A}$ & $0.75: 0.25$ & $0.712: 0.288$ & $0.822: 0.178$ & $0.744: 0.256$ & $0.517: 0.483$ & 0.305 \\
\hline & rs4264407 & Intron & $\mathrm{G}: \mathrm{C}$ & 1.000:0.000 & 0.892:0.108 & 1.000:0.000 & 1.000:0.000 & 0.933:0.067 & 0.108 \\
\hline \multirow[t]{3}{*}{ ITGB7 } & rs11170465 & Intron & G:A & 0.839:0.161 & 0.949:0.051 & 0.92:0.08 & 0.802:0.198 & $0.975: 0.025$ & 0.173 \\
\hline & rs11170466 & Intron & $\mathrm{G}: \mathrm{A}$ & 0.839:0.161 & 0.942:0.058 & 0.898:0.102 & 0.778:0.222 & 0.975:0.025 & 0.197 \\
\hline & rs11574541 & synSNP & C:T & 0.969:0.031 & $1.000: 0.000$ & $1.000: 0.000$ & $1.000: 0.000$ & $1.000: 0.000$ & 0.031 \\
\hline
\end{tabular}


Table 3 continued

\begin{tabular}{|c|c|c|c|c|c|c|c|c|c|}
\hline \multirow[t]{2}{*}{ Gene } & \multirow[t]{2}{*}{ SNP(rs no.) } & \multirow[t]{2}{*}{ Type } & \multirow[t]{2}{*}{ Allele } & \multirow[t]{2}{*}{ Thai $^{\mathrm{a}}$} & \multicolumn{4}{|l|}{ Hapmap $^{\text {b }}$} & \multirow{2}{*}{$\begin{array}{l}\text { Ethnic } \\
\text { difference }\end{array}$} \\
\hline & & & & & Caucasian & Han Chinese & Japanese & African & \\
\hline & rs2272299 & Intron & $\mathrm{G}: \mathrm{A}$ & $0.85: 0.15$ & N/A & 0.9:0.1 & 0.761:0.239 & 0.884:0.116 & 0.139 \\
\hline & rs2272300 & Intron & $\mathrm{T}: \mathrm{G}$ & 0.812:0.188 & $0.942: 0.058$ & 0.9:0.1 & 0.761:0.239 & $0.405: 0.595$ & 0.537 \\
\hline & rs2272301 & Intron & $\mathrm{C}: \mathrm{G}$ & 0.95:0.05 & $0.851: 0.149$ & 0.942:0.058 & $0.872: 0.128$ & 0.982:0.018 & 0.131 \\
\hline & rs3817537 & Intron & G:C & 0.984:0.016 & $1.000: 0.000$ & 0.978:0.022 & 1.000:0.000 & N/A & 0.022 \\
\hline & rs3825084 & Intron & $\mathrm{A}: \mathrm{C}$ & 0.906:0.094 & $0.821: 0.179$ & 0.94:0.06 & 0.805:0.195 & 0.949:0.051 & 0.144 \\
\hline \multirow[t]{10}{*}{ LIPG } & rs2000812 & Intron & $\mathrm{T}: \mathrm{C}$ & $0.633: 0.367$ & $0.8: 0.2$ & $0.522: 0.478$ & $0.42: 0.58$ & 1.000:0.000 & 0.58 \\
\hline & rs2000813 & nsSNP & $\mathrm{C}: \mathrm{T}$ & $0.667: 0.333$ & $0.692: 0.308$ & $0.656: 0.344$ & 0.761:0.239 & $0.966: 0.034$ & 0.31 \\
\hline & rs2276269 & Intron & $\mathrm{T}: \mathrm{C}$ & $0.6: 0.4$ & $0.417: 0.583$ & $0.667: 0.333$ & $0.738: 0.262$ & $0.067: 0.933$ & 0.671 \\
\hline & rs3744843 & UTR & A:G & 0.922:0.078 & N/A & 0.744:0.256 & $0.726: 0.274$ & $0.667: 0.333$ & 0.255 \\
\hline & rs3786247 & UTR & $\mathrm{A}: \mathrm{C}$ & $0.732: 0.268$ & $0.931: 0.069$ & $0.557: 0.443$ & $0.545: 0.455$ & $0.642: 0.358$ & 0.386 \\
\hline & rs3786248 & UTR & $\mathrm{A}: \mathrm{G}$ & 0.938:0.062 & 0.933:0.067 & $0.756: 0.244$ & $0.727: 0.273$ & 1.000:0.000 & 0.273 \\
\hline & rs3819166 & Intron & G:A & $0.6: 0.4$ & 0.808:0.192 & $0.511: 0.489$ & $0.432: 0.568$ & 1.000:0.000 & 0.568 \\
\hline & rs3826577 & UTR & $\mathrm{A}: \mathrm{T}$ & 0.938:0.062 & 0.933:0.067 & $0.756: 0.244$ & $0.727: 0.273$ & 1.000:0.000 & 0.273 \\
\hline & rs6507931 & Intron & $\mathrm{C}: \mathrm{T}$ & 0.833:0.167 & $0.425: 0.575$ & 0.833:0.167 & 0.909:0.091 & 0.492:0.508 & 0.484 \\
\hline & rs9958734 & UTR & $\mathrm{T}: \mathrm{C}$ & $0.75: 0.25$ & $0.946: 0.054$ & $0.605: 0.395$ & 0.583:0.417 & 0.839:0.161 & 0.363 \\
\hline \multirow[t]{6}{*}{ SCARB1 } & rs11057824 & Intron & $\mathrm{C}: \mathrm{T}$ & $0.667: 0.333$ & $1.000: 0.000$ & $0.622: 0.378$ & $0.486: 0.514$ & 1.000:0.000 & 0.514 \\
\hline & rs11057825 & Intron & $\mathrm{C}: \mathrm{T}$ & $0.646: 0.354$ & $1.000: 0.000$ & $0.567: 0.433$ & $0.444: 0.556$ & $1.000: 0.000$ & 0.556 \\
\hline & rs3825140 & UTR & $\mathrm{C}: \mathrm{T}$ & 0.783:0.217 & 1.000:0.000 & $0.622: 0.378$ & $0.524: 0.476$ & N/A & 0.476 \\
\hline & rs4765615 & Intron & $\mathrm{C}: \mathrm{T}$ & $0.5: 0.5$ & 0.509:0.491 & $0.655: 0.345$ & $0.697: 0.303$ & 0.491:0.509 & 0.206 \\
\hline & rs5889 & synSNP & $\mathrm{C}: \mathrm{T}$ & 0.708:0.292 & 0.992:0.008 & $0.58: 0.42$ & $0.464: 0.536$ & 1.000:0.000 & 0.536 \\
\hline & rs5892 & synSNP & $\mathrm{C}: \mathrm{T}$ & 0.906:0.094 & $1.000: 0.000$ & $0.977: 0.023$ & $0.965: 0.035$ & 0.892:0.108 & 0.108 \\
\hline SELPLG & rs2228315 & nsSNP & G:A & 0.808:0.192 & 0.908:0.092 & $0.756: 0.244$ & $0.83: 0.17$ & $0.617: 0.383$ & 0.291 \\
\hline \multirow[t]{3}{*}{ TGFB2 } & rs900 & UTR & $\mathrm{A}: \mathrm{T}$ & $0.281: 0.719$ & N/A & N/A & N/A & $0.667: 0.333$ & 0.386 \\
\hline & rs10482823 & Intron & $\mathrm{T}: \mathrm{C}$ & 0.984:0.016 & $1.000: 0.000$ & 0.989:0.011 & 0.989:0.011 & 1.000:0.000 & 0.016 \\
\hline & rs6684205 & Intron & $\mathrm{A}: \mathrm{G}$ & $0.266: 0.734$ & 0.808:0.192 & $0.278: 0.722$ & $0.227: 0.773$ & $0.525: 0.475$ & 0.581 \\
\hline \multirow[t]{4}{*}{ TGFB3 } & rs3917147 & Intron & $\mathrm{T}: \mathrm{C}$ & 0.969:0.031 & $1.000: 0.000$ & 0.911:0.089 & 0.966:0.034 & $0.667: 0.333$ & 0.333 \\
\hline & rs3917187 & Intron & G:A & $0.55: 0.45$ & 0.731:0.269 & $0.44: 0.56$ & $0.616: 0.384$ & $0.357: 0.643$ & 0.374 \\
\hline & rs3917200 & Intron & $\mathrm{T}: \mathrm{C}$ & $0.95: 0.05$ & $0.944: 0.056$ & $0.966: 0.034$ & 0.911:0.089 & 0.708:0.292 & 0.258 \\
\hline & rs3917201 & Intron & $\mathrm{A}: \mathrm{G}$ & 0.839:0.161 & 0.708:0.292 & $0.444: 0.556$ & $0.58: 0.42$ & $0.625: 0.375$ & 0.395 \\
\hline \multirow[t]{5}{*}{ TGFBR2 } & rs1155705 & Intron & $\mathrm{A}: \mathrm{G}$ & $0.297: 0.703$ & 0.683:0.317 & $0.3: 0.7$ & 0.33:0.67 & 0.608:0.392 & 0.386 \\
\hline & rs1155708 & Intron & G:A & $0.297: 0.703$ & $0.675: 0.325$ & $0.3: 0.7$ & 0.33:0.67 & 0.608:0.392 & 0.378 \\
\hline & rs2276767 & Intron & $\mathrm{C}: \mathrm{A}$ & $0.875: 0.125$ & $0.667: 0.333$ & 0.889:0.111 & 0.911:0.089 & 0.942:0.058 & 0.275 \\
\hline & rs2276768 & Intron & $\mathrm{C}: \mathrm{T}$ & $0.567: 0.433$ & 0.898:0.102 & $0.8: 0.2$ & $0.67: 0.33$ & 0.707:0.293 & 0.331 \\
\hline & rs9843942 & Intron & G:A & 0.734:0.266 & 0.616:0.384 & $0.557: 0.443$ & $0.583: 0.417$ & 0.382:0.618 & 0.352 \\
\hline \multirow[t]{13}{*}{ TGFBR3 } & rs10874913 & Intron & $\mathrm{C}: \mathrm{T}$ & 0.969:0.031 & 1.000:0.000 & 1.000:0.000 & $1.000: 0.000$ & N/A & 0.031 \\
\hline & rs11165376 & Intron & $\mathrm{A}: \mathrm{G}$ & $0.683: 0.317$ & 0.31:0.69 & $0.477: 0.523$ & $0.573: 0.427$ & 0.563:0.438 & 0.373 \\
\hline & rs11165377 & Intron & $\mathrm{C}: \mathrm{T}$ & 0.906:0.094 & $0.742: 0.258$ & 0.689:0.311 & $0.9: 0.1$ & 0.92:0.08 & 0.231 \\
\hline & rs11165378 & Intron & $\mathrm{T}: \mathrm{C}$ & $1.000: 0.000$ & 1.000:0.000 & 1.000:0.000 & $1.000: 0.000$ & 0.942:0.058 & 0.058 \\
\hline & rs12069176 & Intron & $\mathrm{A}: \mathrm{G}$ & $0.367: 0.633$ & 0.686:0.314 & $0.533: 0.467$ & 0.411:0.589 & $0.467: 0.533$ & 0.319 \\
\hline & rs1805109 & UTR & G:A & 0.661:0.339 & 0.915:0.085 & N/A & N/A & 0.936:0.064 & 0.275 \\
\hline & rs1805110 & nsSNP & $\mathrm{C}: \mathrm{T}$ & $0.661: 0.339$ & 0.907:0.093 & $0.551: 0.449$ & $0.557: 0.443$ & $0.877: 0.123$ & 0.356 \\
\hline & rs1805117 & UTR & A:G & 0.859:0.141 & $0.78: 0.22$ & 0.936:0.064 & 0.841:0.159 & 0.956:0.044 & 0.176 \\
\hline & rs2279455 & Intron & $\mathrm{T}: \mathrm{C}$ & 0.589:0.411 & $0.333: 0.667$ & $0.778: 0.222$ & $0.67: 0.33$ & $0.381: 0.619$ & 0.445 \\
\hline & rs2296621 & Intron & $\mathrm{C}: \mathrm{A}$ & $0.659: 0.341$ & $0.75: 0.25$ & $0.956: 0.044$ & 0.841:0.159 & 0.911:0.089 & 0.297 \\
\hline & rs2306886 & Intron & G:A & $0.733: 0.267$ & N/A & $0.644: 0.356$ & 0.789:0.211 & N/A & 0.145 \\
\hline & rs2306887 & Intron & $\mathrm{C}: \mathrm{T}$ & $0.714: 0.286$ & N/A & $0.676: 0.324$ & $0.667: 0.333$ & N/A & 0.047 \\
\hline & rs2306888 & synSNP & $\mathrm{T}: \mathrm{C}$ & 0.933:0.067 & $1.000: 0.000$ & $0.878: 0.122$ & 0.795:0.205 & 1.000:0.000 & 0.205 \\
\hline
\end{tabular}


Table 3 continued

\begin{tabular}{|c|c|c|c|c|c|c|c|c|c|}
\hline \multirow[t]{2}{*}{ Gene } & \multirow[t]{2}{*}{ SNP(rs no.) } & \multirow[t]{2}{*}{ Type } & \multirow[t]{2}{*}{ Allele } & \multirow[t]{2}{*}{ Thai $^{\mathrm{a}}$} & \multicolumn{4}{|l|}{ Hapmap $^{\text {b }}$} & \multirow{2}{*}{$\begin{array}{l}\text { Ethnic } \\
\text { difference }\end{array}$} \\
\hline & & & & & Caucasian & Han Chinese & Japanese & African & \\
\hline & rs284176 & Intron & G:A & $0.667: 0.333$ & $0.664: 0.336$ & 0.544:0.456 & $0.545: 0.455$ & 0.703:0.297 & 0.159 \\
\hline & rs3738441 & Intron & $\mathrm{C}: \mathrm{T}$ & $0.5: 0.5$ & 0.792:0.208 & $0.367: 0.633$ & $0.3: 0.7$ & 0.619:0.381 & 0.492 \\
\hline & rs6696224 & Intron & A:G & $0.633: 0.367$ & 0.917:0.083 & $0.522: 0.478$ & 0.411:0.589 & 0.792:0.208 & 0.506 \\
\hline & rs6699304 & Intron & $\mathrm{C}: \mathrm{T}$ & 0.969:0.031 & $0.825: 0.175$ & 1.000:0.000 & 0.9:0.1 & $0.9: 0.1$ & 0.175 \\
\hline & rs7524066 & Intron & G:T & 0.812:0.188 & $0.664: 0.336$ & 0.944:0.056 & 0.878:0.122 & 0.542:0.458 & 0.402 \\
\hline
\end{tabular}

${ }^{a}$ Allele frequency of the Thai population was determined by direct sequencing of DNA-pooled two samples selected from 32 unrelated Thai b Allele frequencies were determined from data obtained by searching the Hapmap database (http://www.hapmap.org). SNP of some genes are not included in this table because of lacked of information in the Hapmap database

${ }^{c}$ Ethnic differences in allele frequency were calculated by subtracting the lowest allele frequency of the minor allele from the highest allele frequency of the minor allele among the ethnic groups for each SNP site
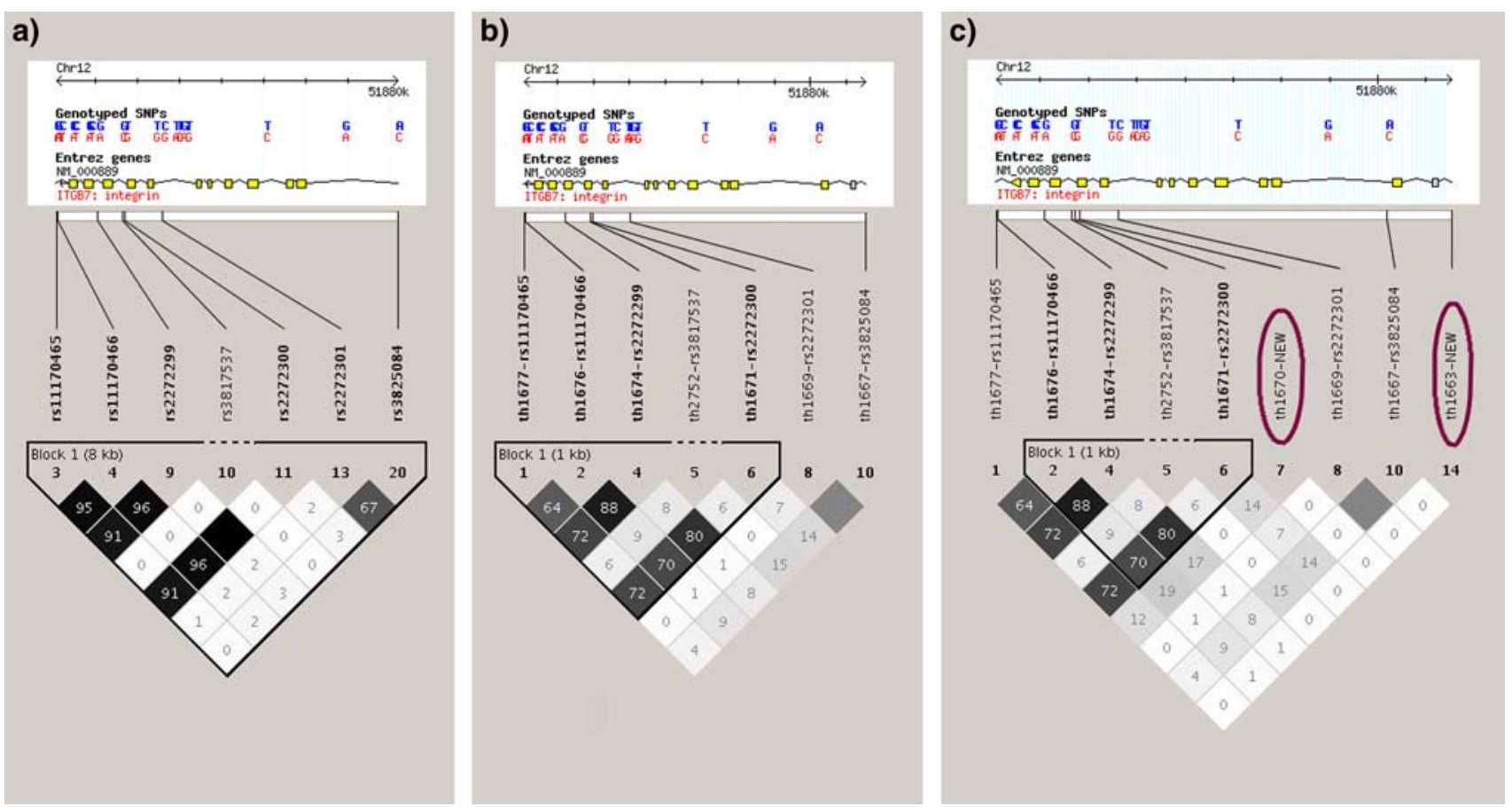

Fig. 3 The haplotype-block definition of the ITGB7 gene comparing Japanese and Chinese HapMap data (a), Thai population without novel single nucleotide polymorphism (SNP) data (b), and Thai population with novel SNPs (c) using confidence intervals (Gabriel

However, these novel SNPs are still important to consider for high-resolution association study design.

The ethnic differences between these SNPs could be responsible for differences in gene regulation and differences in the prevalence of diseases among these ethnic groups. Because of this, allele frequencies in the Thai population were compared with Chinese, Japanese, Caucasian, African, and average allele frequencies in dbSNP. Not surprisingly, the results showed that the allele frequency distribution of the Thai population was more correlated to other Asian populations, Chinese and et al. 2002) in the Haploview software. SNP locations linked to the physical map on the chromosome are shown on the white rectangle. The novel SNPs are marked by red ovals

Japanese, than to Caucasian and African populations. Correlation coefficients were similar to other recent studies (Cha et al. 2004; Kim et al. 2005; Mahasirimongkol et al. 2006). When compared with a similar study performed on the Korean population (Kim et al. 2005), the allele frequency of Korean populations was very similar to that of the Japanese population (correlation coefficient $r=0.907$ ), whereas it had very different patterns of allele frequency compared with Caucasian (correlation coefficient $r=0.359$ ) or African (correlation coefficient $r=0.156$ ) populations. When focusing only on the correlation 
Table 4 Number of tag single nucleotide polymorphisms (SNPs) selected from resequencing data, number of tag SNPs selected from data verified by the National Center for Biotechnology Information (NCBI) and percentage of tag SNPs efficiency

\begin{tabular}{lccccc}
\hline Gene & $\begin{array}{l}\text { No. of tag SNPs } \\
\text { from resequencing } \\
\text { data }\left(N_{\mathrm{RT}}\right)\end{array}$ & $\begin{array}{l}\text { No. of total SNPs } \\
\text { from resequencing } \\
\text { process }\left(N_{\mathrm{R}}\right)\end{array}$ & $\begin{array}{l}\text { No. of tag SNPs } \\
\text { from data verified } \\
\text { by NCBI }\left(N_{\mathrm{DT}}\right)\end{array}$ & $\begin{array}{l}\text { No. of total } \\
\text { SNPs validated } \\
\text { by NCBI }\left(N_{\mathrm{D}}\right)\end{array}$ & $\begin{array}{l}\text { Percentage } \\
\text { of tag SNP } \\
\text { efficiency }(\%)\end{array}$ \\
\hline APOA1 & 8 & 8 & 7 & 7 & 100.00 \\
CCL1 & 4 & 4 & 3 & 3 & 100.00 \\
CCL2 & 4 & 4 & 4 & 4 & 0.00 \\
ITGAM & 20 & 31 & 11 & 19 & 75.00 \\
ITGAX & 18 & 23 & 9 & 9 & 64.29 \\
ITGB7 & 9 & 14 & 7 & 12 & 100.00 \\
LIPG & 18 & 24 & 15 & 18 & 50.00 \\
SCARB1 & 17 & 17 & 11 & 11 & 100.00 \\
SELPLG & 3 & 3 & 1 & 1 & 100.00 \\
TGFB2 & 4 & 5 & 3 & 4 & 100.00 \\
TGFB3 & 6 & 6 & 4 & 4 & 100.00 \\
TGFBR2 & 7 & 10 & 6 & 9 & 100.00 \\
TGFBR3 & 19 & 26 & 17 & 23 & 66.67 \\
TOTAL & 137 & 175 & 98 & 124 & 81.23 \\
\hline
\end{tabular}

Table 5 Assessment of the 16 nonsynonymous single nucleotide polymorphisms (SNPs) in the 13 cardiovascular-related genes using SIFT, PolyPhen, and SNP3D

\begin{tabular}{|c|c|c|c|c|c|c|c|c|}
\hline Gene (protein ID) & $\begin{array}{l}\text { ThaiSNP } \\
\text { ID }\end{array}$ & $\begin{array}{l}\text { NCBI SNP } \\
\text { ID }\end{array}$ & Frequency & AA variant & SIFT score* & $\begin{array}{l}\text { SIFT } \\
\text { prediction }\end{array}$ & $\begin{array}{l}\text { PolyPhen } \\
\text { prediction }\end{array}$ & $\begin{array}{l}\text { SNPs3D } \\
\text { prediction }\end{array}$ \\
\hline APOA1 (NP_000030) & th49 & New & $\mathrm{G}[0.969] / \mathrm{A}[0.031]$ & A61T & 1.00 & Tolerant & Benign & Neutral \\
\hline CCL1 (NP_002972) & th197 & New & $\mathrm{T}[0.969] / \mathrm{G}[0.031]$ & $\mathrm{I} 63 \mathrm{R}$ & 0.00 & Intol & PRB & NA \\
\hline \multirow[t]{4}{*}{ ITGAM (NP_000623) } & th1604 & rs1143679 & $\mathrm{G}[0.969] / \mathrm{A}[0.031]$ & $\mathrm{R} 77 \mathrm{H}$ & 0.47 & Tolerant & Benign & Neutral \\
\hline & th1617 & rs7201448 & $\mathrm{C}[0.933] / \mathrm{T}[0.067]$ & $\mathrm{A} 858 \mathrm{~V}$ & 0.19 & Tolerant & Benign & Neutral \\
\hline & th1624 & New & $\mathrm{G}[0.984] / \mathrm{T}[0.016]$ & M951I & 0.38 & Tolerant & Benign & Neutral \\
\hline & th1630 & rs1143678 & $\mathrm{C}[0.933] / \mathrm{T}[0.067]$ & P1146S & 0.49 & Tolerant & Benign & Neutral \\
\hline \multirow[t]{3}{*}{ ITGAX (NP_000878) } & th1643 & rs12928508 & $\mathrm{G}[0.923] / \mathrm{A}[0.077]$ & $\mathrm{A} 251 \mathrm{~T}$ & 1.00 & Tolerant & Benign & Neutral \\
\hline & th1645 & rs2230429 & $\mathrm{C}[0.5] / \mathrm{G}[0.5]$ & P517R & 0.00 & Intol & PRB & Damaging \\
\hline & th1650 & New & $\mathrm{C}[0.983] / \mathrm{G}[0.017]$ & P720A & 0.00 & Intol & PRB & Damaging \\
\hline \multirow[t]{2}{*}{ SELPLG (NP_002997) } & th1720 & New & $\mathrm{T}[0.922] / \mathrm{C}[0.078]$ & Y297H & 0.25 & Tolerant & Benign & Neutral \\
\hline & th1717 & rs2228315 & $\mathrm{G}[0.808] / \mathrm{A}[0.192]$ & M62I & 0.00 & Intol & Benign & Neutral \\
\hline \multirow[t]{2}{*}{ LIPG (NP_006024) } & th247 & New & $\mathrm{C}[0.981] / \mathrm{T}[0.019]$ & $\mathrm{R} 54 \mathrm{C}$ & 0.00 & Intol & PRB & Damaging \\
\hline & th250 & rs2000813 & $\mathrm{C}[0.667] / \mathrm{T}[0.333]$ & T111I & 0.00 & Intol & Benign & Neutral \\
\hline TGFBR2 (NP_003233) & th1752 & New & $\mathrm{C}[0.969] / \mathrm{T}[0.031]$ & R193W & 0.00 & Intol & PRB & Neutral \\
\hline \multirow[t]{2}{*}{ TGFBR3 (NP_003234) } & th1770 & New & $\mathrm{T}[0.984] / \mathrm{C}[0.016]$ & F142L & 0.71 & Tolerant & POS & NA \\
\hline & th1758 & rs1805110 & $\mathrm{C}[0.661] / \mathrm{T}[0.339]$ & $\mathrm{S} 15 \mathrm{~F}$ & 0.03 & Intol & Benign & NA \\
\hline
\end{tabular}

$N C B I$ National Center for Biotechnology Information, $A A$ amino acid, Intol Intolerant, $P O S$ possibly damaging, $P R B$ probably damaging, $N A$ no data or SNP analysis available

* TI scores $\leq 0.05$ are predicted to be Intolerant, whereas TI scores $>0.05$ are tolerant variants

coefficient $(r)$ among the Asian population, the Thai population and combined Chinese-Japanese frequencies had a higher correlation than between the Thai population and Chinese or Japanese populations. These results support the findings of the international HapMap consortium that the Chinese and Japanese populations are insignificantly different (The International HapMap 2005). Consistent with their population histories, the admixture event between Thai and Chinese is believed to have occurred quite some time ago. Although the allele frequency distribution of the Thai population was similar to the other Asian populations, there are some rare allele markers (rs11574541 and rs10874913) found only in the Thai population but not in other Asian populations.

For LD-block comparison, most novel SNPs were located out of the block defined by known SNPs. Some of them were formed a new LD block, but there were no LDblock formations of mostly novel SNPs. The number of 
blocks might reflect population age, suggesting the greater LD block is the older population. We found a lower number of blocks than in other Asian populations, in which the referred age of the Thai population was younger than other Asian populations. Only $5.77 \%$ of the novel SNPs appear in the defined haplotype block. The LD blocks might be affected by the lower allele frequencies observed for the novel SNPs found in our study. These data indicate that using published SNP data alone would not have adequate coverage of the target region associated with disease. SNP discovery approaches can help identify causative SNPs, which were not reported in the public SNP databases.

When the number of tag SNPs of these two groups was compared, the average tag SNP efficiency (see "Materials and methods") was 81.23. Eight of 13 genes showed $100 \%$ tag SNP efficiency, that is, each of the newly discovered SNPs were also defined as tag SNPs. Therefore, additional SNP discovery is needed to assemble a map for use in the Thai population. The tag SNP results showed concordance to the LD-block results. Consequently, our data agree with the study of Carlson et al. (2003), who suggested that the study of populations other than European Americans required additional SNP discovery before conclusions can be drawn as to the adequacy of dbSNP for each population.

Additionally, SNP location is another factor that influences the selection of prominent SNPs for further association studies. Using three commonly known algorithms for protein function damaging SNP prediction, several novel SNPs located in coding regions were found to likely affect the alteration of protein function. This hypothesis should be investigated further using experimental functional assays to determine their corresponding effects.

In summary, resequencing is a powerful method to discover novel SNPs and SNPs that are specific to certain ethnic groups. This approach could also reveal the distribution of SNPs along interesting genes, which will be useful for future association studies. Consequently, this SNP discovery project provided sufficient information for marker selection used in case-control association studies utilizing candidate gene approaches.

Acknowledgments We thank Justin Dantzer for designing figures used in this article and Lang Li and Jeesun Jung for helpful advice. CT received the postdoctoral fellowship from the National Center for Genetic Engineering and Biotechnology, Thailand, under the Thailand SNP Discovery Project. SP is funded by Thailand Center for Excellence in Life Sciences (TCELS) under the Postdoctoral Scholarships Program. SDM is funded by NIH K22LM009135.

\section{References}

Asztalos BF (2004) High-density lipoprotein metabolism and progression of atherosclerosis: new insights from the HDL Atherosclerosis Treatment Study. Curr Opin Cardiol 19:385-391
Barrett JC, Fry B, Maller J, Daly MJ (2005) Haploview: analysis and visualization of $\mathrm{LD}$ and haplotype maps. Bioinformatics 21:263-265

Brown CM, Rea TJ, Hamon SC, Hixson JE, Boerwinkle E, Clark AG, Sing CF (2006) The contribution of individual and pairwise combinations of SNPs in the APOA1 and APOC3 genes to interindividual HDL-C variability. J Mol Med V84:561-572

Carlson CS, Eberle MA, Rieder MJ, Smith JD, Kruglyak L, Nickerson DA (2003) Additional SNPs and linkage-disequilibrium analyses are necessary for whole-genome association studies in humans. Nat Genet 33:518-521

Cha PC, Yamada R, Sekine A, Nakamura Y, Koh CL (2004) Inference from the relationships between linkage disequilibrium and allele frequency distributions of 240 candidate SNPs in 109 drug-related genes in four Asian populations. J Hum Genet 49:558-572

de Bakker PI, Yelensky R, Pe'er I, Gabriel SB, Daly MJ, Altshuler D (2005) Efficiency and power in genetic association studies. Nat Genet 37:1217-1223

Department of Medical Service Thailand G (2006a) Statistical report. (http://www.dms.moph.go.th/statreport/index.html)

Department of Medical Service Thailand G (2006b) Statistical report of cardiovascular disease in Thai population. (http://www.dms. moph.go.th/statreport/2547/table0647.htm)

Disabella E, Grasso M, Marziliano N, Ansaldi S, Lucchelli C, Porcu E, Tagliani M, Pilotto A, Diegoli M, Lanzarini L, Malattia C, Pelliccia A, Ficcadenti A, Gabrielli O, Arbustini E (2006) Two novel and one known mutation of the TGFBR2 gene in Marfan syndrome not associated with FBN1 gene defects. Eur J Hum Genet 14:34-38

Do H, Vasilescu A, Diop G, Hirtzig T, Coulonges C, Labib T, Heath SC, Spadoni JL, Therwath A, Lathrop M, Matsuda F, Zagury JF (2006) Associations of the IL2Ralpha, IL4Ralpha, IL10Ralpha, and IFN (gamma) R1 cytokine receptor genes with AIDS progression in a French AIDS cohort. Immunogenetics 58:89-98

Fuki IV, Blanchard N, Jin W, Marchadier DH, Millar JS, Glick JM, Rader DJ (2003) Endogenously produced endothelial lipase enhances binding and cellular processing of plasma lipoproteins via heparan sulfate proteoglycan-mediated pathway. J Biol Chem 278:34331-34338

Gabriel SB, Schaffner SF, Nguyen H, Moore JM, Roy J, Blumenstiel B, Higgins J, DeFelice M, Lochner A, Faggart M, Liu-Cordero SN, Rotimi C, Adeyemo A, Cooper R, Ward R, Lander ES, Daly MJ, Altshuler D (2002) The structure of haplotype blocks in the human genome. Science 296:2225-2229

Hoh J, Matsuda F, Peng X, Markovic D, Lathrop MG, Ott J (2003) SNP haplotype tagging from DNA pools of two individuals. BMC Bioinform 4:14

Ishida T, Choi SY, Kundu RK, Spin J, Yamashita T, Hirata K, Kojima Y, Yokoyama M, Cooper AD, Quertermous T (2004) Endothelial lipase modulates susceptibility to atherosclerosis in apolipoprotein-E-deficient mice. J Biol Chem 279:45085-45092

Jaye M, Lynch KJ, Krawiec J, Marchadier D, Maugeais C, Doan K, South V, Amin D, Perrone M, Rader DJ (1999) A novel endothelial-derived lipase that modulates HDL metabolism. Nat Genet 21:424-428

Kim JY, Moon SM, Ryu HJ, Kim JJ, Kim HT, Park C, Kimm K, Oh B, Lee JK (2005) Identification of regulatory polymorphisms in the TNF-TNF receptor superfamily. Immunogenetics 57:297303

Laukkanen J, Yla-Herttuala S (2002) Genes involved in atherosclerosis. Exp Nephrol 10:150-163

Maglott D, Ostell J, Pruitt KD, Tatusova T (2005) Entrez Gene: genecentered information at NCBI. Nucleic Acids Res 33:D54-D58

Mahasirimongkol S, Chantratita W, Promso S, Pasomsab E, Jinawath $\mathrm{N}$, Jongjaroenprasert W, Lulitanond V, Krittayapoositpot P, 
Tongsima S, Sawanpanyalert P, Kamatani N, Nakamura Y, Sura T (2006) Similarity of the allele frequency and linkage disequilibrium pattern of single nucleotide polymorphisms in drug-related gene loci between Thai and northern East Asian populations: implications for tagging SNP selection in Thais. J Hum Genet 51:896-904

Matyas G, Arnold E, Carrel T, Baumgartner D, Boileau C, Berger W, Steinmann B (2006) Identification and in silico analyses of novel TGFBR1 and TGFBR2 mutations in Marfan syndrome-related disorders. Hum Mutat 27:760-769

McCarthy JJ, Lehner T, Reeves C, Moliterno DJ, Newby LK, Rogers WJ, Topol EJ (2003) Association of genetic variants in the HDL receptor, SR-B1, with abnormal lipids in women with coronary artery disease. J Med Genet 40:453-458

McDermott DH, Yang Q, Kathiresan S, Cupples LA, Massaro JM, Keaney JF Jr, Larson MG, Vasan RS, Hirschhorn JN, O'Donnell CJ, Murphy PM, Benjamin EJ (2005) CCL2 polymorphisms are associated with serum monocyte chemoattractant Protein-1 levels and myocardial infarction in the Framingham Heart Study. Circulation 112:1113-1120

Michiels S, Danoy P, Dessen P, Bera A, Boulet T, Bouchardy C, Lathrop M, Sarasin A, Benhamou S (2007) Polymorphism discovery in 62 DNA repair genes and haplotype-associations with risks for lung, and head and neck cancers. Carcinogenesis (in press)

Mizuguchi T, Collod-Beroud G, Akiyama T, Abifadel M, Harada N, Morisaki T, Allard D, Varret M, Claustres M, Morisaki H, Ihara M, Kinoshita A, Yoshiura K, Junien C, Kajii T, Jondeau G, Ohta T, Kishino T, Furukawa Y, Nakamura Y, Niikawa N, Boileau C, Matsumoto N (2004) Heterozygous TGFBR2 mutations in Marfan syndrome. Nat Genet 36:855-860

Ng PC, Henikoff S (2002) Accounting for human polymorphisms predicted to affect protein function. Genome Res 12:436-446

R Development Core Team G (2006) R: a language and environment for statistical computing

Ramensky V, Bork P, Sunyaev S (2002) Human non-synonymous SNPs: server and survey. Nucleic Acids Res 30:3894-900

Rozen S, Skaletsky H (2000) Primer3 on the WWW for general users and for biologist programmers. Methods Mol Biol 132:365-386

Ruano G, Seip RL, Windemuth A, Zollner S, Tsongalis GJ, Ordovas J, Otvos J, Bilbie C, Miles M, Zoeller R, Visich P, Gordon P,
Angelopoulos TJ, Pescatello L, Moyna N, Thompson PD (2006) Apolipoprotein A1 genotype affects the change in high density lipoprotein cholesterol subfractions with exercise training. Atherosclerosis 185:65-69

Schneider M, Tognolli M, Bairoch A (2004) The Swiss-Prot protein knowledgebase and ExPASy: providing the plant community with high quality proteomic data and tools. Plant Physiol Biochem 42:1013-1021

Simon DI, Chen Z, Seifert P, Edelman ER, Ballantyne CM, Rogers C (2000) Decreased neointimal formation in Mac-1-/- mice reveals a role for inflammation in vascular repair after angioplasty. J Clin Invest 105:293-300

Singh NN, Ramji DP (2006) The role of transforming growth factorbeta in atherosclerosis. Cytokine Growth Factor Rev 17:487-499

Tabara Y, Kohara K, Yamamoto Y, Igase M, Nakura J, Kondo I, Miki T (2003) Polymorphism of the monocyte chemoattractant Protein (MCP-1) gene is associated with the plasma level of MCP-1 but not with carotid intima-media thickness. Hypertens Res 26:677683

Tabibiazar R, Wagner RA, Ashley EA, King JY, Ferrara R, Spin JM, Sanan DA, Narasimhan B, Tibshirani R, Tsao PS, Efron B, Quertermous T (2005) Signature patterns of gene expression in mouse atherosclerosis and their correlation to human coronary disease. Physiol Genom 22:213-226

Takahashi M, Matsuda F, Margetic N, Lathrop M (2002) Automated identification of single nucleotide polymorphisms from sequencing data. Proc IEEE Comput Soc Bioinform Conf 1:87-93

The Innate Immunity PGA P (2000) IIPGA genetic data: ITGAM allele frequencies. (https://innateimmunity.net/IIPGA2/PGAs/ InnateImmunity/ITGAM/allele_freqs?flavor=masked)

The International HapMap C (2005) A haplotype map of the human genome. Nature 437:1299-1320

Wang X, Le Roy I, Nicodeme E, Li R, Wagner R, Petros C, Churchill GA, Harris S, Darvasi A, Kirilovsky J, Roubertoux PL, Paigen B (2003) Using advanced intercross lines for high-resolution mapping of HDL cholesterol quantitative trait loci. Genome Res 13:1654-1664

Yue P, Melamud E, Moult J (2006) SNPs3D: candidate gene and SNP selection for association studies. BMC Bioinform 7:166 